\title{
Different Technology in Designing Vending Machine
}

\author{
D Sridhar Raja, Abinethri. R,T.Vijayan
}

\begin{abstract}
The vending machine is a kind of cash driven machine that automatically distributes snacks, drinks and other consumer products automatically. Consumer pay coin into a slot, once a choice is made by pressing the push button, the machine dispenses the item purchased. Money, card or coin-based product vending machine by using embedded microcontrollers; Arduino and Raspberry Pi are currently used in systems. By using these microcontrollers, it is complicated when there was a technical error. In this review paper, we have created a multi-product coin type vending machine by using Mitsubishi PLC. The Programming Logic Controller (PLC) used automatically to monitor and control with high speed, efficiency, and reliability. Switch ON the power supply. Put the coin in the coin acceptor, and then select the product by pressing push button. The motor starts rotating along with the spring and moves the selected item until it released from the spring. The Hall Effect sensor used to count the rotation with the help of the magnet to sense. When the product released from the spring the motor stop rotating and the released product is ready to dispense. [1],[3],[5]

Keywords : Hall effect sensor, DC motor, coin acceptor, PLC(Programmable Logic Controller).
\end{abstract}

\section{INTRODUCTION}

A vending machine is a type of money based machine that distributes products quickly and automatically. In 1880, the first selling machine in Egyptian temples was set up for dispensing water in return of coins discovered by the Greek mathematician and engineer Heron of Alexandria. There are various types of product vending machines such as snacks, tickets, etc. There are more than 25 individual vending machines. Dubai Mall found the first gold seller Gold to Go vending machine in the United Arab Emirates. This machine is protected by armored gaurds. This ATM splits out 24 carat gold in 320 different styles: gold bars, coins and jewelry. [2 ],[ 4],[6]

Nowadays, most product vending machines use microcontrollers, arduino and raspberry pi. By using these controllers, programming is very difficult when the product is expanding. PLC compared with, the microcontroller will perform limited and less work operations. The microcontroller cannot directly communicate with high power and has a complex structure. A microcontroller only performed with limited number of executions simultaneously and is usually used on micro devices. Microcontrollers cannot

Revised Manuscript Received on August 22, 2019.

Sridhar Raja D Department of EIE, Bharath Institute of Higher Education and Research, Tamilnadu, India. Email: sridharraja.eie@bharathuniv.ac.in

R.Abinethri, Department of EIE, Bharath Institute of Higher education and research, Tamilnadu, India. Email: abi.eie@ bharathuniv.ac.in

T.Vijayan, Department of EIE, Bharath Institute of Higher education and research, Tamilnadu, India. Email: vijayan.eie@bharathuniv.ac.in communicate with all protocols and the MC's scan rotation time is slow.

Therefore, we have created a number of product coin type vending machine by interacting with the Mitsubishi PLC. The Programming Logic Controller (PLC) is used to automate the machine by operating switches, sensors and motors. Compared with other microcontrollers, PLC programming and the development time is limited. In PLC, I / O capacity and memory are higher than microcontrollers. Processing time is faster than other microcontroller. PLC will communicate with various protocols and will be reliable with any applications. PLC can also work in the hazardous area, but the microcontrollers cannot work. The advantage of the PLC is that it can work in both AC as well as in DC. Failure is less likely to be compared to other controllers. [19],[20],[21]

\section{PlC(Programmable logic Controller)}

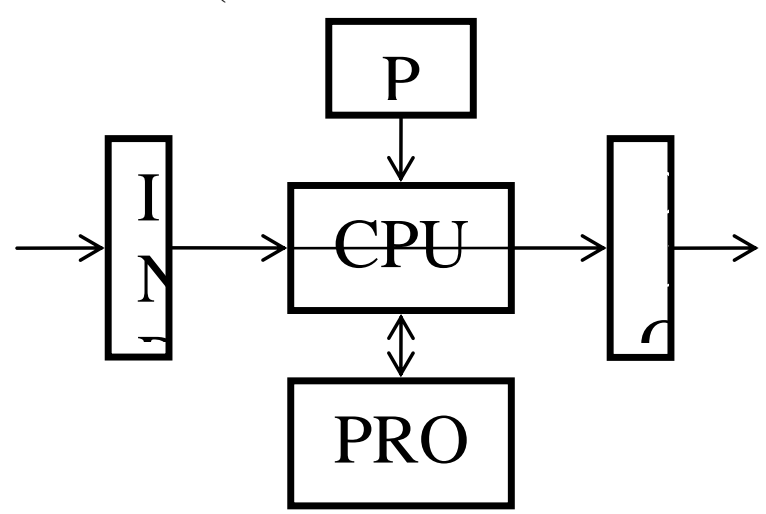

Fig.1.Block Diagram of PLC

A programmable logic controller (PLC) is a special form of microprocessor-based control, which preserves programmable memory instructions and controls machines and processes to implement logic, sorting, timing, calculation, and mathematics. These control systems are specially designed to survive in harsh environments and protect against heat, cold, dust and moisture. They are basically used to control automated systems in the industry. Now they are the most advanced and simpler control systems that are now heavily replacing the harder wire curve relays.

There are two types of PLC relay type and transistor type. Transistor type PLC is used only for high speed motors. We use FX1N 14MR PLC with 8 inputs and 6 relay outputs. [7], [ 9], [11]

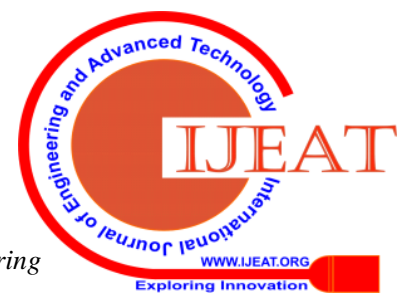




\section{BLOCK DIAGRAM}

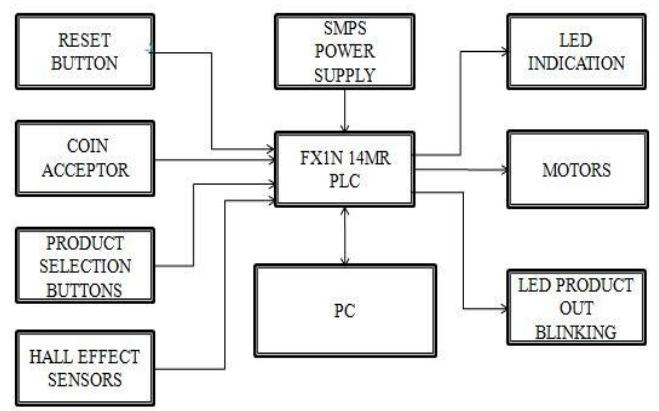

Fig.2.Block Diagram of Vending Machine

Input sources replace real-time analogue power signals to digital electrical signals, and these signals are applied to the PLC via connector.These input signals are stored in PLC external memory. This is done by the CPU.Control logic or program algorithms are written in the programming device and stored in user memory.The CPU receives these instructions from user memory and enables input signals through manipulating, computing, and processing by activating them to control output devices.Execution of the result is stored in external memory that controls the output drives.CPU has a check on output signals and keeps updating the contents of input memory according to changes in output memory. [8],[10],[12]

\section{IV.CAD DESIGN OF VENDING MACHINE}

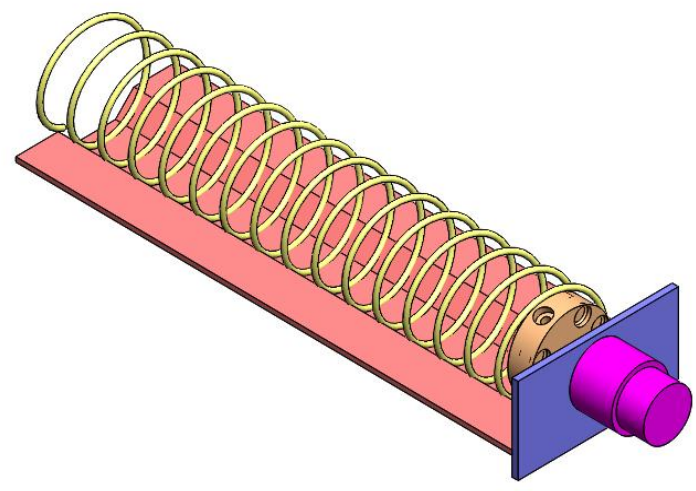

Fig.3.CADD Design for Spring

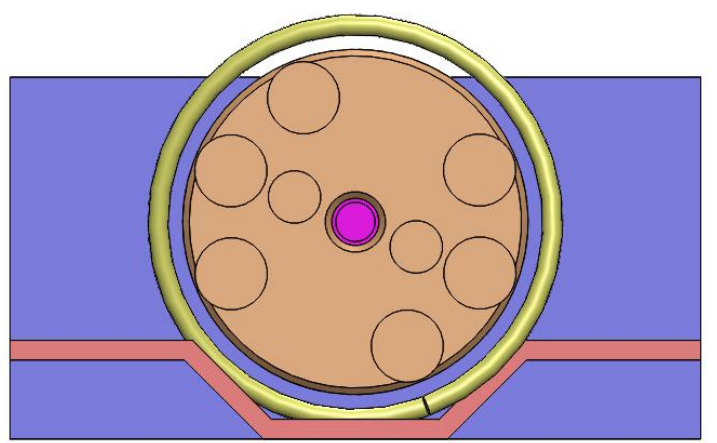

Fig.4.CADD Design for Position of Magnet \& Motor

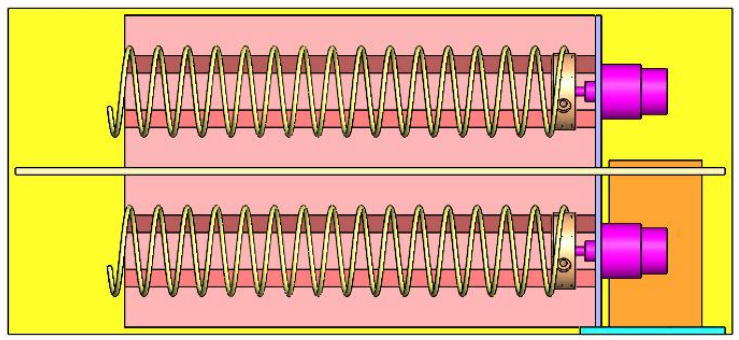

Fig.5.CADD Design for Spring Setup in Vending Machine

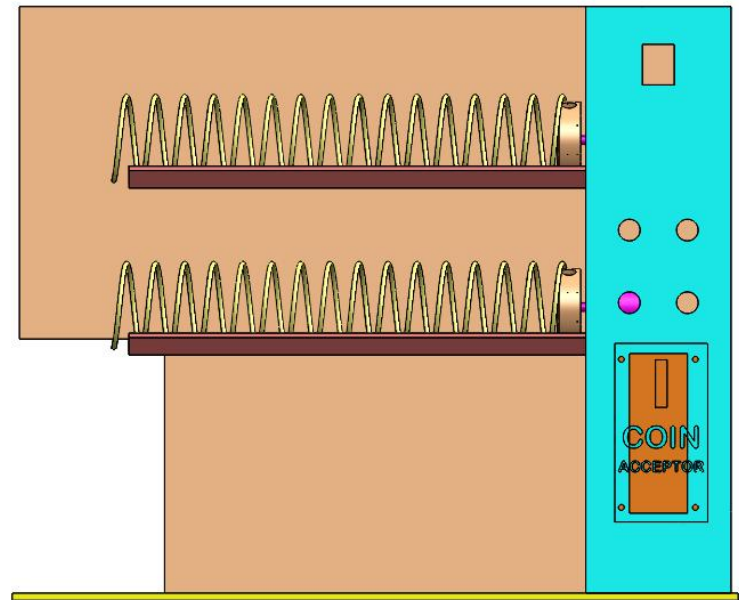

Fig.6.Front Side Design for Vending Machine Using CAD

\section{CONCLUSION}

In this review paper, we discussed about the various papers on similar techniques. Further it is decided to implement at laboratory level using PLC as a controller and probably we will get expected output as the multi-product vending machine. [14],[16], [18]

Design of the vending machine described by four types of products and the number can be further increased. The operation of the vending machine was based on the coin detector and four different motors which sends items out. In future, we have planned to enhance with HMI based multi-product vending machine. We can use smart card or QR code based transaction instead of coin acceptor. [13], [15] ,[ 17]

\section{REFERENCES}

[1] Sharma, R.K., Irusapparajan, G. \& Periyaazhagar, D. 2019 , "Three-phase symmetric cascading Z-source seven levels multilevel inverter excited by multi carrier sinusoidal pulse width modulation scheme", International Journal of Innovative Technology and Exploring Engineering, vol. 8, no. 10, pp. 4269-4274.

[2] Velavan, R., Bharanidharan, S. \& Sheeba, B. 2019, "EMF pollution Causes, effects and protection", International Journal of Innovative Technology and Exploring Engineering, vol. 8, no. 9 Special Issue 3, pp. 1166-1168

[3] Saravana, S., Balaji, S., Arulselvi, S. \& John Paul Praveen, A. 2019 "Reliable power quality monitoring and protection system", International Journal of Innovative Technology and Exploring Engineering, vol. 8, no. 9 Special Issue 3, pp. 644-645

[4] Tamil Selvan, S. \& Sundararajan, M. 2019, "Performance Parameters of 3 Value 8t Cntfet Based Sram Cell Design Using H-Spice", International Journal of Recent Technology and Engineering, vol. 8, no. 2 Special issue 5, pp. 22-27. 
[5] Jac Fredo, A.R., Abilash, R.S., Femi, R., Mythili, A. \& Kumar, C.S. 2019, "Classification of damages in composite images using Zernike moments and support vector machines", Composites Part B: Engineering, vol. 168, pp. 77-86.

[6] Kathiravan, P. \& Govindaraju, C. 2019, "Design and evaluation of ultra gain isolated DC-DC converter for photovoltaic system", International Journal of Engineering and Advanced Technology, vol. 8, no. 5, pp. 2646-2651.

[7] Kripa, N., Vasuki, R. \& Kishore Kanna, R. 2019, "Realtime neural interface controlled au-pair BIMA bot", International Journal of Recent Technology and Engineering, vol. 8, no. 1, pp. 992-994.

[8] Mohanraj, Meenaa Kumari, M., Philomina, S. \& Jasmin, M. 2019, "In-situ humidity measurement of hydrogen fuel cell car using MEMS sensor", International Journal of Recent Technology and Engineering, vol. 8 , no. 1 , pp. 41-43.

[9] Velmurugan, T. \& Prakash, S. 2019, "Artificial intelligent based distribution automation of swift fault detection isolation and power restoration for HT network", International Journal of Innovative Technology and Exploring Engineering, vol. 8, no. 6, pp. 1-6.

[10] Dwarakesh, K. \& Prem Kumar, G. 2019, "Five-level inverter based sequential boost system using fuzzy logic controller", International Journal of Innovative Technology and Exploring Engineering, vol. 8, no. 6, pp. 12-19.

[11] Anne Gifta, A. \& Hemavathi, G. 2019, "Analysis of grid tied solar PV system using ANFIS Algorithm", International Journal of Innovative Technology and Exploring Engineering, vol. 8, no. 6, pp. 312-316.

[12] Jayavel, R., Rangaswamy, T.R. \& Prakash, S. 2019, "Efficient grid management system with renewable and conventional power sources", International Journal of Innovative Technology and Exploring Engineering, vol. 8, no. 6, pp. 287-289.

[13] Hemavathi, G. \& Maheshwaran, S. 2019, "Proportional resonant controlled high gain step-up converter system with improved response", International Journal of Innovative Technology and Exploring Engineering, vol. 8, no. 6, pp. 317-323.

[14] Periyaazhagar, D. \& Irusapparajan, G. 2019, "Design and completion of asymmetric single phase 27 level cascaded mli for various pwm scheme", International Journal of Innovative Technology and Exploring Engineering, vol. 8, no. 6, pp. 792-797.

[15] Mahalakshmi, V. \& Vijayaragavan, S.P. 2019, "PV based power electronic converters for high voltage DC applications", International Journal of Recent Technology and Engineering, vol. 7, no. 6, pp. 670-674.

[16] Irusapparajan, G., Periyaazhagar, D., Prabaharan, N. \& Rini Ann Jerin, A. 2019, "Experimental verification of trinary DC source cascaded h-bridge multilevel inverter using unipolar pulse width modulation", Automatika, vol. 60, no. 1, pp. 19-27.

[17] Sangeetha, G., Sherine, S., Arputharaju, K. \& Prakash, S. 2019, "On Line Monitoring of Higher Rated Alternator using Automated Generator Capability Curve Administer", Proceedings of the IEEE International Conference on \&amp;quot;Recent Trends in Electrical, Control and Communication\&amp;quot; RTECC 2018, pp. 176.

[18] Bycil, V.J. \& Wiselin, M.C.J. 2019, "Modeling and analysis of vibration energy harvesting system using piezo stack", International Journal of Mechanical and Production Engineering Research and Development, vol. 9, no. Special Issue 1, pp. 523-533.

[19] Sripada, A., Warrier, A., Kapoor, A., Gaur, H. \& Hemalatha, B. 2018 , "Dynamic lateral balance of humanoid robots on unstable surfaces", International Conference on Electrical, Electronics, Communication Computer Technologies and Optimization Techniques, ICEECCOT 2017, pp. 539.

[20] Srinivasan, S., Thirumalaivasan, K. \& Sivakumaran, T.S. 2018 , "Performance evaluation of double-output luo converters", Journal of Advanced Research in Dynamical and Control Systems, vol. 10, no. 10 Special Issue, pp. 870-878.

[21] Karthikayen, A. \& Selvakumar Raja, S. 2018, "A skellam distribution inspired trust factor-based selfish node detection technique in MANETs", Journal of Advanced Research in Dynamical and Control Systems, vol. 10, no. 13, pp. 940-949.

\section{AUTHORS PROFILE}

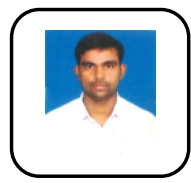

D.Sridhar Raja, Assistant Professor, Department of EIE,Bharath Institute of Higher education and research, Tamilnadu, India

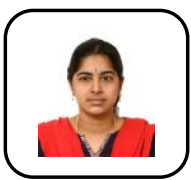

R.Abinethri, Assistant Professor, Department of EIE,Bharath Institute of Higher education and research, Tamilnadu, India

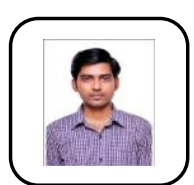

T.Vijayan, Assistant Professor, Department of EIE,Bharath Institute of Higher education and research, Tamilnadu, India. 